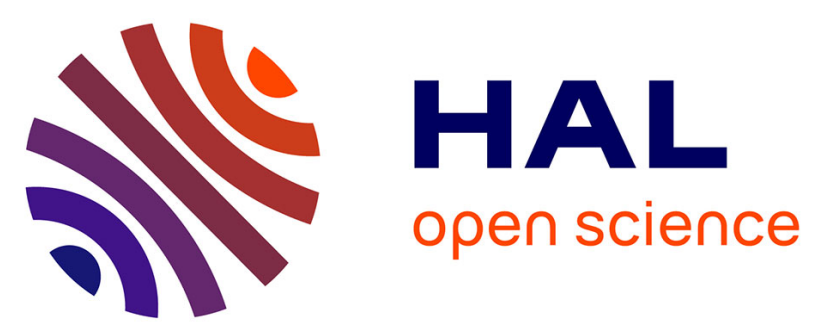

\title{
How reimbursement databases can be used to support drug utilisation studies: example using the main French national health insurance system database
}

Philippe Latry, Mathieu Molimard, Bernard Bégaud, Karin Martin-Latry

\section{- To cite this version:}

Philippe Latry, Mathieu Molimard, Bernard Bégaud, Karin Martin-Latry. How reimbursement databases can be used to support drug utilisation studies: example using the main French national health insurance system database. European Journal of Clinical Pharmacology, 2010, 66 (7), pp.743748. 10.1007/s00228-010-0819-0 . hal-00589490

\section{HAL Id: hal-00589490 \\ https://hal.science/hal-00589490}

Submitted on 29 Apr 2011

HAL is a multi-disciplinary open access archive for the deposit and dissemination of scientific research documents, whether they are published or not. The documents may come from teaching and research institutions in France or abroad, or from public or private research centers.
L'archive ouverte pluridisciplinaire HAL, est destinée au dépôt et à la diffusion de documents scientifiques de niveau recherche, publiés ou non, émanant des établissements d'enseignement et de recherche français ou étrangers, des laboratoires publics ou privés. 


\title{
How reimbursement databases can be used to support drug utilisation studies: example using the main French national health insurance system database
}

\author{
Philippe Latry • Mathieu Molimard • Bernard Bégaud • \\ Karin Martin-Latry
}

Received: 22 September 2009 / Accepted: 24 March 2010 / Published online: 29 April 2010

(C) Springer-Verlag 2010

\begin{abstract}
Introduction Reimbursement databases are potentially invaluable tools to develop and conduct pharmacoepidemiological studies on drug use. However, two types of factors that may influence the performance of a database can be distinguished: firstly, factors related to the constitution of the database, and secondly, factors related to the data. For the latter, we think that two are important: the presence of the drug in the database and the capacity to capture real-life use, both of which are influenced by the marketing status (e.g., OTC) and whether reimbursement is possible.

Objectives To illustrate and discuss to what extent reimbursement databases are relevant tools to conduct drug utilization studies with regard to the data on drugs.

Methods In order to illustrate the reliability of data in reimbursement databases, data from the main French national
\end{abstract}

\section{P. Latry}

Echelon régional du service médical

de l'assurance maladie d'Aquitaine,

80 avenue de la Jallère,

33000 Bordeaux, France

M. Molimard $\cdot$ B. Bégaud $\cdot$ K. Martin-Latry $(\bowtie)$

Département de Pharmacologie,

Université Victor Segalen Bordeaux 2,

Bordeaux, France

e-mail: karin.latry@u-bordeaux2.fr

M. Molimard • B. Bégaud $\cdot$ K. Martin-Latry

Inserm U 657,

Bordeaux, France

M. Molimard $\cdot$ B. Bégaud $\cdot$ K. Martin-Latry

CHU,

Bordeaux, France health insurance database (55 million individuals) were compared to national drug sales in France (units) during the same year.

Results Depending on the ATC class, the capture in the database of drugs actually sold ranged from 32 to $81 \%$.

Discussion Capture of classes of drugs in the database may be explained by the specific characteristics of the French health insurance system (reimbursable drugs, OTC market share). These characteristics influence the studies that can be performed both in terms of the topic but also the methodology. This problem probably exists for the other reimbursement databases used worldwide.

Conclusion Studies should be designed according to the strengths and weaknesses of reimbursement databases that were not originally developed for pharmacoepidemiology.

Keywords Databases · Pharmacoepidemiology Health insurance $\cdot$ Reimbursement $\cdot$ France

\section{Introduction}

Reimbursement databases are potentially invaluable tools to develop and conduct pharmacoepidemiological studies on drug use and are extensively used [1]. Compared to fieldbased studies, database studies present numerous advantages such as rapid access to a large number of patients and data but also the real observational character of the information gathered. However, a problem that is classically mentioned is the validity of the data, i.e., the concordance between real-life use and data from databases. Two types of factors may be distinguished. Firstly, there are factors related to the structure of the database: the population covered by the database may be limited to an administrative region (e.g., Saskatchewan), a socio- 
demographic category (e.g., Medicaid for the elderly), a treatment setting (e.g., ambulatory), or a population with a particular occupation (which is the case in France). Secondly, there are factors related to the data. In this case, two parameters are of great importance: the reimbursement of the drug (and thus its presence in the database) and the capacity to capture real-life use. The presence of a drug, or class of drugs, depends on the reimbursement policy of the organization concerned. For example, in reimbursement databases of private health insurance companies, such as health maintenance organizations (HMOs), several drugs may be excluded owing to nonreimbursement. Similar situations exist for public health insurance systems. Regional differences exist in the reimbursement of vaccines by the Medicaid system [2], and in France, third-generation oral contraceptives are not reimbursed. The capacity to capture real-life use also depends on the health insurance policy but also on the patients. Indeed, data regarding certain drugs may be of limited value for research owing to an annual expenditure limit, beyond which medications have to be paid out-of-pocket by patients, and patients could decide not to claim reimbursement of a drug [3]. Additionally, reimbursement may depend on indication. For example, in the French national health insurance system one of the marketed forms of sumatriptan is not reimbursed for the treatment of cluster headache, while it is reimbursed for the treatment of migraine. Furthermore, adherence to treatment may of course contribute to the degree of capture.

The relative importance of the parameters related to the data will influence the data available on drugs in such databases and thus the use and conclusions of any study performed. In the current study this is illustrated using the major reimbursement database of the French national health insurance system, one of the largest in the world.

\section{Methods}

France has a publicly funded health system that systematically covers the population. Within this system, three main insurance schemes provide reimbursement for health services. The insurance scheme with which individuals are affiliated depends on their employment, but the modalities of drug reimbursement are identical for all French health insurance systems.

The Caisse Nationale de l'Assurance Maladie des Travailleurs Salariés (Cnam-TS) is the main French health insurance system both in terms of the number of covered patients and in terms of reimbursement expenditure. It covers all the medical reimbursement of all employees and their families and covers $87 \%$ of the population in France, i.e., 55 million individuals. All reimbursement data are centralized in a single database called Erasme.
The Cnam-TS publishes a yearly report (Medic'AM) from the Erasme database detailing the number of reimbursed drug delivery units (boxes or delivery devices) bought from community pharmacies [4]. To determine the ability of the Erasme database to capture drugs, the Medic'AM data for 2004 was compared to the national drug sales for the same year obtained from the French Medicines Agency [Agence française de sécurité sanitaire des produits de santé (Afssaps)],, which compiles pharmaceutical industry reports of drug delivery units sold to community pharmacies each year [5], including parallel imports [6], and is considered as a gold standard source of information on the French market.

We used data from 2004 because, at the time we performed this study, the data of the French Medicines Agency were available only through 2006, and the Agency indicated in its report that the most recent data could change and thus that it was recommended that these not be used [5]. Ninety classes of drugs were investigated but only some of those with sufficient sales $(>1$ million delivery units) were retained for illustrative purposes.

Both the Cnam-TS and the Afssaps use the ATC classification system, the Afssaps only describing second level codes. Thus the comparison was performed at this level by comparing the number of drugs reimbursed in each ATC class (second level codes) to the number of drugs available on the French market. It would have been interesting to compare the defined daily dose, but this information was not completely available for the two sources of data. The proportion of pharmaceutical forms (i.e., tablet, suppository, syrup...) available over-the-counter (OTC) in a class and the average price in euros of a delivery unit for all drugs marketed in France were also obtained. The presence of drugs available OTC in each class was determined from a French government report on the OTC market [7]. According to this report, the proportion of each class available OTC was classified as follows: null when the class had no OTC drug, low for up to $20 \%$ available OTC, medium for up to $50 \%$, and high above $50 \%$.

At this point it is necessary to explain how the drug market works in France. Firstly, in France there is a pharmaceutical monopoly and thus, all drugs are only available in pharmacies (community or hospital). Secondly two notions are tightly linked: that of delivery and that of reimbursement. When a drug is delivered (by a pharmacist) it is either prescribed or not prescribed. Certain drugs are prescription-only; others are available with or without prescription (OTC). Concerning reimbursement by the public health insurance system, for a drug to be reimbursed it needs to be on the list of reimbursable drugs and it needs to be prescribed. For example, third-generation oral contraceptives are prescription-only and thus require prescription to be delivered but are not reimbursed. Acetaminophen may be reimbursed and is available with a prescription or OTC, 
but will only be reimbursed if it is prescribed. Drugs in France are delivered in nondivisible units, often corresponding to 1 month's supply, irrespective of the prescribed quantity. There is no limitation on the amount of drugs to be sold with or without prescription. Drugs prescribed and purchased by the population receive different levels of reimbursement $(0,15,35,65$, or $100 \%)$ that are set by the government for each drug when it gains market authorization. This drug reimbursement policy is the same for all health insurance schemes in France. The French market for drugs in terms of prescription/reimbursement is illustrated in Fig. 1.

\section{Results}

Table 1 shows the great variability in the proportion of drugs captured in the Erasme database of the total number sold. Depending on the ATC class, it ranged from 32 to $81 \%$ [93\% if non-steroidal anti-inflammatory drugs (NSAIDs) are taken into account)]. More than two-thirds of the prescription-only classes were found to have been captured in the database at least at a level of $60 \%$. These classes mostly correspond to treatments for chronic disease. Average price of a delivery unit ranged from $€ 2$ (GB£1.8 or US\$2.6) to $€ 33$ (GB£29.4 or US\$43.7) but most remained below $€ 15$. The proportion of OTC drugs was high when capture was below $60 \%$. The only exception was for the ATC code G03 (i.e., sex hormones and modulators of the genital system) where the proportion of OTC was low although $57 \%$ of the drugs were captured in the Erasme database (Table 1).

\section{Discussion}

The results show that the ability of the Erasme database to capture drug sales differed greatly among the ATC classes considered. Thus the use of this database to conduct a drug utilization study should be evaluated prior to performing a study. This variation did not seem to be associated with cost as the mean price was homogeneous. Despite no clear separation regarding OTC availability, the majority of the classes with high capture had a minority of products available OTC (proportion null to medium) and the level of OTC was high when capture was below $60 \%$. Thus the percentage of OTC in the class seems to influence the capture. In the case of the ATC code G03, where the level of OTC is low, the low capture is due to the nonreimbursement of third-generation oral contraceptives (Table 1). The proportion of capture for NSAIDs is striking but may be due to misclassification. Indeed, NSAIDs have two to four different ATC codes according to the substance concerned: for example, the ATC codes for ibuprofen are G02CC01, M01AE01, M02AA13, and M01AE51 [8]. Thus, it is possible that the two sources of data use ATC in a different manner, which may induce misclassification, but we are not able to verify this point.

The national health insurance systems in France impose no annual expenditure limit on any drug, and the vast majority of drugs are reimbursed, which helps explain why capture in the database was seemingly not affected by price. However, to be reimbursed the drugs need to be prescribed, which excludes capture of drugs obtained OTC. This is illustrated by a study reported by Lacroix et al. who did not succeed in assessing OTC use during pregnancy using the French health insurance reimbursement database of southeastern France [9]. Furthermore, certain prescription-only drugs, for example thirdgeneration oral contraceptives, are prescription-only but are not reimbursed. Such drugs belong to the ATC code G03: "sex hormones and modulators of the genital system" and account for approximately $40 \%$ of the oral contraceptives sold in community pharmacies in France [5]. This precludes use of reimbursement databases to investigate these, for example with regard to their safety [10]. Additionally, phosphodiesterase-5 inhibitors (e.g., sildenafil, vardenafil) are not reimbursed for their main indication, erectile dysfunction, which limits the use of this database to
Fig. 1 French market for drugs in 2004 in terms of quantity: status of prescription/reimbursement. Source: Afssaps Report, 2008 [5]

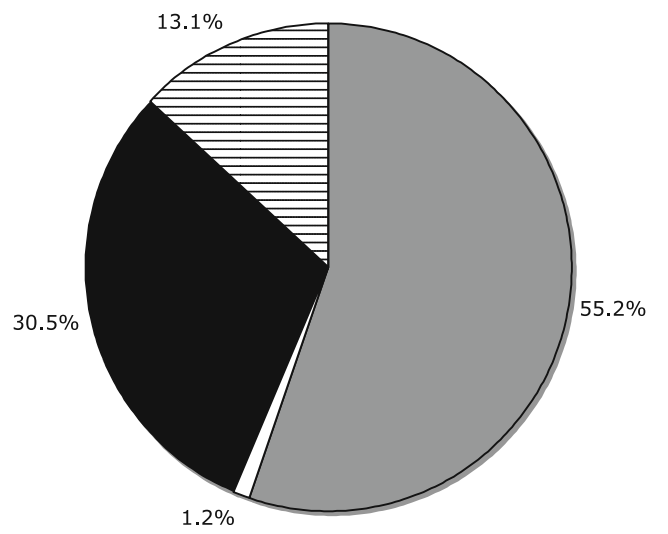

$\square$ Prescription-only drugs reimbursable (most of the drugs)

$\square$ Non-reimbursable prescription-only drugs (for example third generation oral contraceptives)

Drugs available with prescription reimbursed or OTC (for example acetaminophen)

$\boxminus$ Drugs available with prescription not reimbursed or OTC (for example vitamins) 
Table 1 Database capture of drug sales in France during 2004 for ambulatory-care patients. Details of the therapeutic subgroup, the percentage of drugs sold that were captured in the database, the proportion of the substances available over-the-counter (OTC) in the class, and the mean price per unit box are shown

\begin{tabular}{|c|c|c|c|c|c|}
\hline \multicolumn{2}{|c|}{$\begin{array}{l}\text { Units sold that were } \\
\text { captured in the } \\
\text { database }(\%)\end{array}$} & \multirow{2}{*}{$\begin{array}{l}\text { Class of drug } \\
\text { NSAIDs }\end{array}$} & \multirow{2}{*}{$\begin{array}{l}\text { ATC code } \\
\text { M01 }\end{array}$} & \multirow{2}{*}{$\begin{array}{l}\text { Proportion of drugs } \\
\text { marketed in France } \\
\text { available OTC }\end{array}$} & \multirow{2}{*}{$\begin{array}{l}\text { Mean price of a } \\
\text { delivery unit }(€)\end{array}$} \\
\hline$>70 \%$ & 93 & & & & \\
\hline & 81 & Antiepileptics & N03 & Null & 14 \\
\hline & 77 & Vaccines & J07 & Medium & 11.8 \\
\hline & 75 & Hypolipidemics & $\mathrm{C} 10$ & Null & 8.1 \\
\hline & 75 & Psycholeptics & N05 & Low & 6.6 \\
\hline & 72 & Antibacterials for systematic use & J01 & Null & 5.3 \\
\hline & 71 & Antihypertensives & $\mathrm{C} 02$ & Null & 7.6 \\
\hline \multirow[t]{8}{*}{$60-69 \%$} & 69 & Psychoanaleptics & N06 & Low & 11.6 \\
\hline & 69 & Antithrombotic agents & B01 & Low & 22 \\
\hline & 68 & Beta-blocking agents & $\mathrm{C} 07$ & Null & 7.8 \\
\hline & 68 & Drugs for acid-related disorders & $\mathrm{A} 02$ & High & 10.7 \\
\hline & 67 & Corticosteroids for systematic use & $\mathrm{H} 02$ & Null & 2.3 \\
\hline & 66 & Agents acting on the renin-angiotensin system & $\mathrm{C} 09$ & Null & 10.6 \\
\hline & 64 & Calcium channel blockers & $\mathrm{C} 08$ & Null & 9.2 \\
\hline & 62 & Anti-Parkinson's drugs & N04 & Null & 17 \\
\hline \multirow[t]{6}{*}{$50-59 \%$} & 58 & Antihistamines for systemic use & R06 & High & 4.4 \\
\hline & 57 & Sex hormones and modulators of the genital system & G03 & Low & 33.2 \\
\hline & 56 & Topical products for joint and muscular pain & M02 & High & 2.4 \\
\hline & 54 & Analgesics & N02 & High & 7.6 \\
\hline & 51 & Nasal preparation & R01 & High & 3 \\
\hline & 50 & Laxatives & A06 & High & 3.4 \\
\hline $40-49 \%$ & 45 & Antidiarrheals, intestinal anti-inflammatory/anti-infective agents & A07 & High & 8 \\
\hline \multirow[t]{3}{*}{$30-39 \%$} & 35 & Stomatological preparations & A01 & High & 2.6 \\
\hline & 34 & Throat preparation & $\mathrm{R} 02$ & High & 2 \\
\hline & 32 & Vitamins & A11 & High & 3 \\
\hline
\end{tabular}

investigate possible nonarteritic anterior ischemic optic neuropathy (NOIAN) [11]. These factors go some way to explain the relatively low capture of drug sales for this class of drug (57\%). OTC availability for this class was marginal, but it may affect the capture of other drugs. For example, acetaminophen is frequently obtained in this way in France, which is reflected in the data presented (ATC code N02 includes acetaminophen).

Studies aiming to assess patterns of use or associated risk should make an attempt to circumvent this limitation. In some countries the market share of OTCs is low and/or the results of the study could be considered as a lower estimate of their effect [12-14]. For example, in Denmark very few NSAIDs are marketed OTC, and it is possible to conduct a study on this class of drugs without fear of major bias [15]. Another parameter to be taken into account is the relative market share that OTCs represent. Certain classes of drugs have a high proportion of products available OTC, but they represent only a small market share. For example, antacids that are available either OTC or with a prescription are frequently obtained OTC but are less used than proton pump inhibitors that are prescription-only and reimbursable. This explains the high proportion of OTC and high capture.

In the Erasme database, most drugs with capture of over $60 \%$ were prescription-only, but there were certain exceptions. For example, most vaccines sold were available OTC, yet they were the second most captured class of drugs. But this is not particularly surprising as most patients will visit their physician for administration of these and most vaccines are reimbursed.

The results observed and the differences between the classes of drug may be found in the other French reimbursement databases as the drug reimbursement policy is the same for all schemes in France. Furthermore, these probably exist in reimbursement databases found internationally as showed by Walley et al. [16]. The authors compared use of statins from 
an administrative database used to reimburse pharmacists with data from a standard commercial source across 14 European countries and demonstrated that administrative databases record lower use [16]. Of course, this problem will depend on the drug reimbursement policy of the considered country, as we mentioned in the introduction.

Such limitations have hindered previously reported studies, for example, Lambert et al., who used the California Medicaid database to assess the risk of developing type 2 diabetes mellitus with atypical antipsychotics, did not tackle the possible effects of exposure to ziprasidone or aripiprazole because neither was in the formulary [17]. Similarly, in an other study reported by Ward et al. who used the Saskatchewan database to study atypical antipsychotic agent compliance and the association with the risks of hospitalization note that the formulary restrictions ensured that the large majority of patients received risperidone, lowering the number of switches in this population [18]. Additionally, Gagne et al. note probable underestimation of the prevalence of drug use among pregnant women because OTC and complementary medicines were not captured in the Italian regional database they used [19].

These variations in capture or presence of drugs have important consequences when a researcher intends to conduct a study using reimbursement databases. If the objective of the study is to characterize a real-life treatment pattern, all the drugs used in the source population must be captured in the database. For an etiological study, i.e., cohort or case-control, nested in the database, concerns regarding generalization of the study results may arise if some drugs, for various reasons, are under- or over-represented in the database when compared to the source population. Similarly, if the objective of the study is to assess the public health impact of the use of a class of drugs, results can be biased if not all drugs are represented. Another point to consider is that several databases do not include data on drugs used in hospitals (e.g., Erasme, GPRD, Medicaid, some HMOs, Memo). Depending on the objective of the study, this could be a concern or not. For example, a study intending to assess the persistence of a drug treatment is prone to underestimate this parameter if a marked proportion of patients had an extended hospitalization [20-23].

The current study presents several limitations. Although it is large, the Erasme database only covers $87 \%$ of the population in France. Other national health insurance systems cover farmers, their employees and the selfemployed, who are also able to obtain drugs from community pharmacies. Drug usage across these populations is unlikely to differ significantly, and thus the maximum capture of sales by the Cnam-TS database was approximately $87 \%$ of sales. The data presented herein were not adjusted for this, as it is impossible to verify the exact market share of the population considered by the Cnam-TS insurance system. This limitation precludes comment on capture in terms of absolute values, but does inform on the relative difference in capture between drug classes. As previously mentioned, the year 2004 was chosen to illustrate the problem owing to questionable validity of more recent data. This may be of limited importance since the type of problem will probably remain, regardless of reimbursement changes. It is also possible that the different use of ATC between the two sources of data may have induced misclassification (see explanation regarding NSAIDs above). Nevertheless, if this problem exists it concerns only a few classes of drugs well known to have several indications and thus several ATC codes. This reinforces the idea that researchers must be aware of how data are coded.

Another point is that every year there are some changes in the reimbursement policy in France, but as the changes have only a minor impact on all the market drugs, this cannot challenge our conclusions. Thus, this parameter does not change the message of this study: one must be aware of the data in the database before using it. There may also be a bias in timing when comparing data captured through the two separate sources since pharmacies may order drugs one month and dispense in another one. This too may be of limited importance because there are no rapid changes in utilization, switching in OTC status or hoarding due to reimbursement changes. Moreover the changes may also be too small to have important consequences on the data presented, which represented a high volume.

Despite these limitations, our results highlight the importance of taking into account the capacity for a reimbursement database to capture drugs. We believe that reimbursement databases, and in particular the Erasme database presented in this paper, are useful tools for pharmacoepidemiological research. Indeed, Erasme includes a large population and most of the drugs marketed in France. Thus, this database has been extensively used for 20 years for epidemiologic and pharmacoepidemiologic research [24]. It is crucial to know the structure of a database, especially if it was not originally developed for pharmacoepidemiological research.

\section{Conclusion}

The example of the Cnam-TS database (Erasme) highlights the importance of understanding the characteristics of reimbursement databases when performing research in order take into account the strengths and weaknesses. This is applicable to other such databases, whatever the country or objective of the study.

Acknowledgments We thank Philip Robinson for assistance in the preparation of this manuscript. 
Contributors: $\mathrm{PhL}, \mathrm{BB}, \mathrm{MM}$ and $\mathrm{KML}$ designed the study. $\mathrm{PhL}$ coordinated data collection. PhL, KML performed analyses. KML, $\mathrm{PhL}, \mathrm{MM}$ interpreted the results. KML, PhL, BB contributed to writing the paper. $\mathrm{PhL}$ is the guarantor for the paper.

Conflict of interest None declared.

\section{References}

1. Strom B (2006) Pharmacoepidemiology. Wiley, Chichester

2. Hennessy S, Carson J, Ray W, Strom B (2006) Medicaid databases. In: Strom B (ed) Pharmacoepidemiology, 4th ed. Wiley, Chichester, pp 281-294

3. Chan K, Davis R, Gunter M, Gurwitz J, Herrinton L, Nelson W, Raebel M, Roblin D, Smith D, Platt R (2006) The HMO research network. In: Strom B (ed) Pharmacoepidemiology, 4th ed. Wiley, Chichester, pp 261-270

4. Securite Sociale, l'Assurance Maladie (2008) Medic-AM 2002-2007. $\mathrm{http}$ ://www.ameli.fr/l-assurance-maladie/statistiques-et-publications/ donnees-statistiques/medic-am-generic-am-biolam-lpp-am/medicam-2002-2007.php. Accessed 12 February 2009

5. Direction de l'Evaluation de la Publicité et des Produits Cosmétiques (2008) Analysis of drugs' sales for community pharmacies and hospitals in France (in French), 8th ed. Afssaps, Saint Denis

6. Article L5121-17 du code de la santé publique. modifié par LOI n²008-1425 du 27 décembre 2008 - art. 177 (V). http://www. legifrance.gouv.fr. Accessed 9 February 2010

7. DRESS (2001) La consommation de médicament non prescrit, no. 105. http://www.sante.gouv.fr/drees/etude-resultat/er-pdf/er105. pdf. Accessed 12 June 2009

8. CNHIM (2010) Theriaque. http://www.theriaque.org/ Accessed 9 February 2010

9. Lacroix I, Hurault C, Sarramon MF, Guitard C, Berrebi A, Grau M, Albouy-Cossard C, Bourrel R, Elefant E, Montastruc JL, Damase-Michel C (2009) Prescription of drugs during pregnancy: a study using EFEMERIS, the new French database. Eur J Clin Pharmacol 65(8):839-846. doi:10.1007/s00228-009-0647-2

10. Szarewski A, Mansour D (1999) The 'pill scare': the responses of authorities, doctors and patients using oral contraceptives. Hum Reprod Update 5:627-632

11. Editorial, Wall Street Journal, May 31, 2005

12. Mikaeloff Y, Kezouh A, Suissa S (2008) Nonsteroidal antiinflammatory drug use and the risk of severe skin and soft tissue complications in patients with varicella or zoster disease. Br J Clin Pharmacol 65(2):203-209
13. Patterson MK, Castellsague J, Walker AM (2008) Hospitalization for peptic ulcer and bleeding in users of selective COX-2 inhibitors and nonselective NSAIDs with special reference to celecoxib. Pharmacoepidemiol Drug Saf 17(10):982-988

14. Wei L, Fahey T, MacDonald TM (2008) Adherence to statin or aspirin or both in patients with established cardiovascular disease: exploring healthy behaviour vs. drug effects and 10-year followup of outcome. Br J Clin Pharmacol 66(1):110-116

15. Fosbol EL, Gislason GH, Jacobsen S, Abildstrom SZ, Hansen ML, Schramm TK, Folke F, Sorensen R, Rasmussen JN, Kober L, Madsen M, Torp-Pedersen C (2008) The pattern of use of nonsteroidal anti-inflammatory drugs (NSAIDs) from 1997 to 2005: a nationwide study on 4.6 million people. Pharmacoepidemiol Drug Saf 17(8):822-833

16. Walley T, Folino-Gallo P, Schwabe U, Van Ganse E, Stephens P (2004) Comparison of national administrative and commercial databases to monitor expenditure and costs of statins across Europe. Eur J Clin Pharmacol 60(7):503-511. doi:10.1007/ s00228-004-0801-9

17. Lambert BL, Chou CH, Chang KY, Tafesse E, Carson W (2005) Antipsychotic exposure and type 2 diabetes among patients with schizophrenia: a matched case-control study of California Medicaid claims. Pharmacoepidemiol Drug Saf 14(6):417-425

18. Ward A, Ishak K, Proskorovsky I, Caro J (2006) Compliance with refilling prescriptions for atypical antipsychotic agents and its association with the risks for hospitalization, suicide, and death in patients with schizophrenia in Quebec and Saskatchewan: a retrospective database study. Clin Ther 28(11):1912-1921

19. Gagne JJ, Maio V, Berghella V, Louis DZ, Gonnella JS (2008) Prescription drug use during pregnancy: a population-based study in Regione Emilia-Romagna, Italy. Eur J Clin Pharmacol 64 (11):1125-1132

20. Perreault S, Dragomir A, Blais L, Berard A, Lalonde L, White M, Pilon D (2009) Impact of better adherence to statin agents in the primary prevention of coronary artery disease. Eur J Clin Pharmacol 65(10):1013-1024. doi:10.1007/s00228-009-0673-0

21. Lachaine J, Rinfret S, Merikle EP, Tarride JE (2006) Persistence and adherence to cholesterol lowering agents: evidence from Regie de l'Assurance Maladie du Quebec data. Am Heart J 152 (1):164-169

22. Catalan VS, LeLorier J (2000) Predictors of long-term persistence on statins in a subsidized clinical population. Value Health 3 (6):417-426

23. Vinker S, Shani M, Baevsky T, Elhayany A (2008) Adherence with statins over 8 years in a usual care setting. Am J Manag Care 14(6):388-392

24. Martin-Latry K, Begaud B (2010) Pharmacoepidemiological research using French reimbursement databases: yes we can! Pharmacoepidemiol Drug Saf 19(3):256-265. doi:10.1002/pds.1912 